\title{
ASSESS THE SATISFACTION REGARDING MATERNAL AND CHILD HEALTH SERVICES AMONG WOMEN OF REPRODUCTIVE AGE GROUP
}

\section{Mrs.Gurpreet Kaur Assistant Professor,Swami Premanand College of Nursing,Mukerian}

ABSTRACT Maternal and child health care is the health service provided to mothers and children. It encompasses the health care dimensions of family planning, preconception, prenatal and postnatal care in order to ensure a positive and fulfilling experience and reduce maternal morbidity and mortality in some cases. Maternal complications and poor perinatal outcome are highly associated with non utilization of antenatal and delivery care services and poor socioeconomic conditions of the patient. It is essential that all pregnant women have access to high quality obstetric care throughout their pregnancies.

KEYWORDS : Satisfaction, Maternal and child health,reproductive age.

\section{INTRODUCTION}

Maternal and child health is a very important component of family welfare services to attain total wellbeing of the child with in the frame work of the family and community. Every aspect of community health services in India has marked effects on the health and welfare of expectant mothers and particularly in infant and children. A World Health Organization expert group (1976) defined mother and child health services as "the promotive, preventive, curative and rehabilitative care for mother and children." The objective of maternal and child health care have been defined as reduction of maternal, prenatal, infant and child mortality and morbidity and promotion of reproductive health. The ultimate objective of maternal and child health services care is lifelong health.

\section{STATEMENT OF THE PROBLEM}

A DESCRIPTIVE STUDY TO ASSESS THE SATISFACTION REGARDING MATERNAL AND CHILD HEALTH SERVICES AMONG WOMEN OF REPRODUCTIVE AGE GROUP IN COMMUNITY HEALTH CENTRE, HAJIPUR.

\section{OBJECTIVES}

1. To assess the satisfaction regarding maternal and child health services among women of reproductive age group.

2. To determine the association of satisfaction regarding maternal and child health services among reproductive age group with selected demographic variables.

\section{REVIEW OF LITERATURE}

A cross-sectional study was conducted to assess the prenatal care satisfaction among 66 mothers attending postnatal care in Ibadan, Nigeria. A survey was used to collect the data. The result revealed that the satisfactory rate among clients was $98.5 \%$ with services and facilities used for their care. The study concluded that the identified causes of dissatisfaction included dirty hospital environment, inadequate water supply and hospital facilities, distance of hospital location, cost of materials, time wasting, inadequate staffing and poor attitude, and verbal and physical abuse (Odetola T, Fakorede E, 2018).

A descriptive study was conducted to determine perceived satisfaction towards utilization of maternal and child health care services among 226 women in district public health care facility Nagrik Hospital Rohtak, Haryana. A systematic random sampling was used to collect the data. An interview technique was followed to conduct the study. The result concluded that 125 beneficiaries was satisfied with the maternal health care services and 101 was satisfied with child health care services. Socio-demographic and accessibility attributes were found statistically insignificant towards perceived satisfaction for utilization pattern of maternal and child health care services. The study concluded that need of hour is to strengthen the maternal and child health care services and conduct regular health education sessions to enhance perceived satisfaction(Dr Arora V, Dr Kharb M, Dr Sinha LN, Dr Nitin Joshi NK, 2017).

\section{RESEARCH METHODOLOGY}

A quantitative approach was adopted for the study to assess the satisfaction among women of reproductive age group (1845) yrs in Community Health Centre, Hajipur. It consists of selfstructured rating scale regarding maternal and child health services. A self-administered questionnaire was used to elicit the information, which include three parts:l.demographic variables 2 . self-structured rating scale regarding maternal and child health services. The data were analyzed by frequency and percentage distribution of sample characteristics and chi-square test.

\section{RESULTS:}

\section{Table 1}

Frequency and percentage distribution of satisfaction regarding maternal and child health services among women of reproductive age group.

\begin{tabular}{|l|l|l|l|}
\hline Level of satisfaction & Score & N & $\%$ \\
\hline Highly & $71-100$ & 20 & 40.0 \\
\hline Moderately & $36-70$ & 20 & 40.0 \\
\hline Unsatisfied & $<35$ & 10 & 20.0 \\
\hline
\end{tabular}

The result showed that maximum (40\%) of women fall in highly satisfaction score and minimum (20\%) of women fall in unsatisfaction score. While analyzing association of satisfaction of women with selected demographic variable, it was found that there is a relationship of age, education, occupation, family income, total number of children, total number of hospital visit, and source of information regarding maternal and child health services. The assumption of the study was that women have highly satisfaction regarding maternal and child health services. Thus, it was proved right because women are highly satisfied regarding the maternal and child health services who belongs to reproductive age Study was concluded that age, education, occupation, family income, number of children, number of hospital visit and source of information had an impact on satisfaction regarding Maternal and Child Health Services.

\section{DISCUSSION}

In this chapter, an attempt has been made to discuss the findings in the study in accordance with the objectives of the research. The investigator interpretatively discuss the result of the study in the discussion. The study was, "A descriptive study to assess the satisfaction regarding maternal and child health services among women of reproductive age group in Community Health Centre, Hajipur." A self-structured rating scale was used to assess the satisfaction regarding maternal and child health services among women of reproductive age 
group. The findings of the present study revealed that $40 \%$ of women was highly satisfied, $40 \%$ of women was moderately satisfied, whereas $20 \%$ of women was unsatisfied regarding maternal and child health services. The findings of the study consistent with the result of study concluded by Bayu H, Merga M 2018 that was a cross-sectional study conducted to assess maternal satisfaction and associated factors among 413 clients admitted to obstetrics and gynaecology wards of public hospitals in Mekelle town, Ethiopia. A systematic sampling methods and questionnaires was used to collect the data. The result revealed that the rate of satisfaction among clients were $79.7 \%$. The study concluded that the clients were dissatisfied towards well-describing side effects of medication, informing what the medication is used for before prescribing and administering, cleanness of toilet and washroom, and access to drinking water, latrine, and handwashing facility.

\section{SUMMARY AND CONCLUSION}

The present study was conducted as an attempt to assess the satisfaction regarding maternal and child health services among women of reproductive age group in Community Health Centre, Hajipur.The study revealed that $40.0 \%$ of women are highly satisfied, $40.0 \%$ of women are moderately satisfied and remaining $20.0 \%$ of women are unsatisfied. There is a statistically significant association of satisfaction regarding maternal and child health services of women with reproductive age with the demographic variables.

\section{REFERENCES}

1. Maternal Health. World health organization.Available from: https:// www. who. int/health-topics/maternal-health\#tab=tab

2. Odetola T, Fakorede E. Assessment of Perinatal Care Satisfaction Amongst Mothers Attending Postnatal Care in Ibadan . 2018. 84(1): 36-46. doi: 10.29024/aogh.10. Available from: https:// www. ncbi. nlm. nih. gov/ pmc/ articles/PMC6748216/.

3. Dr Arora V, Dr Kharb M, Dr Sinha LN, Dr Nitin Joshi NK. Service quality dimensions regarding maternal and child health-care provided to the beneficiaries attending a Nagrik Hospital Rohtak Haryana. International Journal of Medical Science and Public Health 2019 /Volume 8(Issue 12):103945 - December 2019.DOI: 10.5455/ijmsph.2019.0926727092019

4. Bayu H, Merga M. Patient Satisfaction and Associated Factors among Clients Admitted to Obstetrics and Gynecology Wards of Public Hospitals. 2018. https://doi.org/10.1155/2018/2475059. Available from: https:// www. hindawi. com/journals/ogi/2018/2475059/ 